\title{
Role of Graph Theory to Facilitate Landscape Connectivity: Subdivision of a Harary Graph
}

\author{
Khalid Arif $^{1 *}$, Zeeshan Afzal ${ }^{1}$, Muhammad Nadeem ${ }^{1}$, Bilal Ahmad ${ }^{1}$, \\ Azhar Mahmood ${ }^{1}$, Munawar Iqbal ${ }^{2}$, Arif Nazir $^{2}$ \\ ${ }^{1}$ Department of Mathematics and Statistics, University of Lahore, Lahore, Pakistan \\ ${ }^{2}$ Department of Chemistry, University of Lahore, Lahore, Pakistan
}

Received: 22 May 2017

Accepted: 18 July 2017

\begin{abstract}
This work focuses on mapping landscape connectivity by making use of a subdivision of a Harary graph through super edge antimagic total labeling. This study employs a Harary graph by inserting $h$ vertices in each edge, where $h=2 n, n \geq 1$ using the super (a, 2) edge antimagic total labeling and labeling the vertices and edges by taking the difference of arithmetic progression as 2 i.e. $d=2$. We divided this paper into two parts. In first part, when the order of the subdivided harary graphs $p$ varies then the distance $t$ will remain the same, while in the other part, when the order $p$ varies then distance $t$ will also vary.
\end{abstract}

Keywords: Harary graph, super $(a, d)$-EAT, subdivision of Harary graph, landscape connectivity

\section{Introduction}

For a long time the surface and subsurface places have mirrored the social, traditional, and economic features considered as a marker of heritage. This should be passed on to upcoming generations for its protection, and for such an approach landscape connectivity activities should be given priority. The protection and sustainability of an area is a prime objective during modeling of the landscape connectivity design. Mapping landscape connectivity works best at landscape scale, where the given population or species are highly diversified with different forms of connectivity based on geographic information system (GIS) to quantify connectivity [1-8]. A growing number of quantitative approaches facilitate measuring and mapping connectivity, which can integrate large amounts of information needed to evaluate connectivity for a given population or species. Th hour is needed to identify an effective approach for maintaining and restoring connectivity [9-12], and GIS is a valuable technique in this regard [13-17]. A graph represents the landscape as a set of nodes and edges. The nodes are the distinct entities in the landscape where edges represent connectivity between nodes as shown in Fig.1. Edges may or may not be interconnected and deliver information about connectivity [18]. Landscape connectivity is characterized by graph-making with to base on GIS. Some of studies show that a GIS-based approach is used to quantify landscape connectivity [1-8]. Landscapes or networks connect the people in many ways and can be viewed as a network of environmental territory connected by scattering individuals in [19]. The arrangement of a network along with its nodes and connecting lines is worth noticing, as it is one of the growing properties that affects humanity in various ways [20].

*e-mail: khalid.arif@tech.uol.edu.pk 


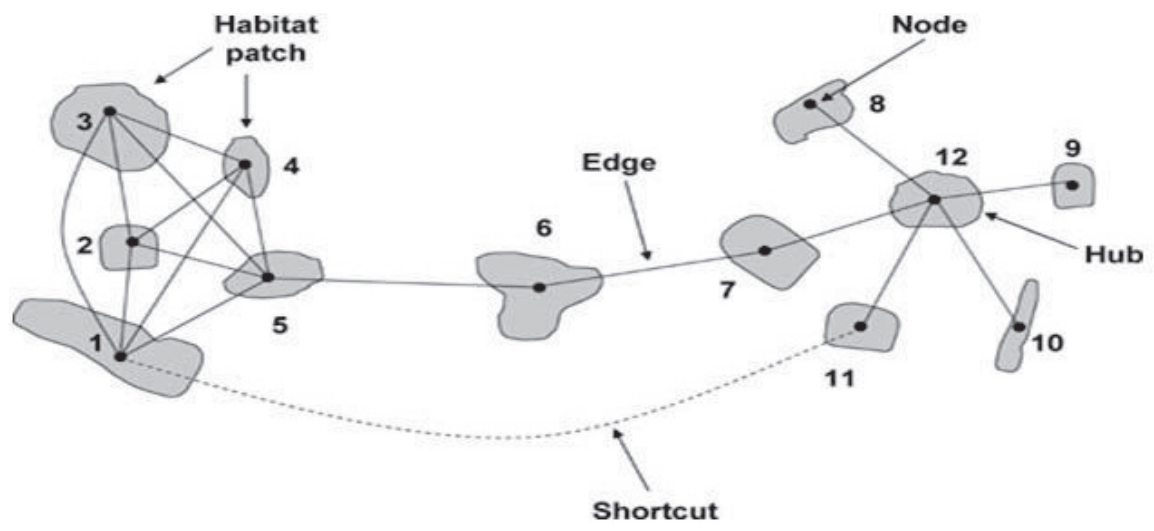

Fig. 1. Landscape connectivity.

In this paper we investigated finite, simple, and undirected graphs. Graph $G$ consists of the vertex-set $V(G)$ and the edge-set $E(G)$.

A graph labeling is a mapping that assigns numbers to graph elements. The domain will be the set of all vertices, the set of all edges, or the set of all vertices and edges in this paper. Total labeling is a labeling in which the domain is set of vertices and edges. If the sum of edge weights constitutes an arithmetic progression with initial term and difference $d$, then the total labeling is said to be $(a, d)$ edge antimagic total labeling. If the least labels are assigned to vertices, then the total labeling is known as super $(a, d)$-edge antimagic total labeling. Harmonius, cordial, graceful, and antimagic are the types of graph labelings. This paper deals with the super $(a, d)$-edge antimagic total labeling.

The super magic labeling was introduced in various classes [21-22]. For $(V, E)$ graph $G$, a bijective mapping $f: V(G) \cup E(G) \rightarrow\{1,2,3, \ldots|V|+|E|\}$ is an edge-magic total labeling of $G$ if $f(x)+f(x y)+f(y)=k$ (constant), where $k$ is a constant, independent of the choice of edge $x y \in E(G)$. The concept of edge magic total labeling and super edge-magic total labeling of graph $G$ was appplied by various authors for landscape connectivity [23-26] as a bijective function $f: V(G) \cup E(G) \rightarrow$ $\{1,2,3, \ldots|V|+|E|\}$, such that in addition to being an edgemagic total labeling of $G$, if it satisfies the extra property that is $f(V(G))=\{1,2,3, \ldots, v\}$. Wallis named this labeling strongly edge-magic.

The concept of antimagic labeling was introduced by Kim and Keown in [27-28]. In their terminology, graph $G$ is called antimagic if its edges are labeled with labels $\{1,2,3, \ldots, e\}$ in such a way that all vertex-weights are pairwise distinct, where a vertex-weight of a vertex $v$ is the sum of labels of all the edges incident with $v$.

An $(a, d)$-EAT labeling of graph $G$ is defined as a oneto-one mapping $f$ from $V(G) \cup E(G)$ to the set $\{1,2,3, \ldots$, $v+e\}$ so that the set of edge-weights $\{f(x)+f(x y)+f(y)$ $: x y \in E(G)\}$ equals $\{a, a+d, a+a 2, \ldots a+(e-1) d\}$ for two integers $a>0$ and $d \geq 0$. Notice that the same labeling would be an edge-magic total labeling when $d=0$. In other words an $(a, 0)$-EAT labeling is an EMT labeling of $G$.
An $(a, d)$-EAT labeling is called super if the smallest labels appear on the vertices of $G$, i.e., $f(V(G))=$ $\{1,2,3, \ldots, v\}$. The $(a, d)$-edge antimagic total labeling and super $(a, d)$-edge antimagic total labelings are natural extensions of the notion of an edge-magic total labeling [29-31].

Ngurah et al. [9] proved that $m C_{n}(n \geq 3)$ has an $(a, d)-$ edge antimagic total labeling in the following cases:

$(a, d)=\left(\frac{5 m n}{2}+2,1\right)$, where $m$ is even, $(a, d)=(2 m n+2,2)$,

$(a, d)=\left(\frac{3 m n+5}{2}, 3\right)$ for $m$ and $n$ odd, $(a, d)=((m n+3), 4)$

for $m$ and $n$ odd, and $m C_{n}$ has a super $(2 m n+2,1)$-edge antimagic total labeling. They also proved that the following $C_{n}$ has a super $(a, d)$-edge antimagic total labeling if either $d$ is 0 or 2 and $n$ is odd, or $d=1$; for odd $(n \geq 3)$ and $m=1$ or 2 , the generalized Peterson graph $P(n, m)$ has a super $\left(\frac{11 n+3}{2}, 0\right)$-edge antimagic total labeling and a super $\left(\frac{5 n+5}{2}, 2\right)$-edge antimagic total labeling; and for odd $n \geq 3, P\left(n, \frac{n-1}{2}\right)$ has a super $\left(\frac{11 n+3}{2}, 0\right)$-edge antimagic total labeling and a super

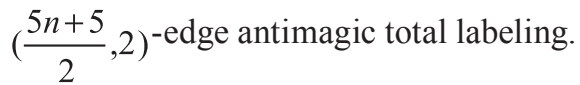

Super edge-antimagic total labeling for Harary graphs $C_{p}^{t}$ was constructed by Hussain et al. [28]. They worked on super $(a, d)$-edge antimagic total labeling and super $(a, d)$-vertex antimagic total labeling. They also constructed the super edge-antimagic and super vertexantimagic total labelings for a disjointed union of $k$ identical copies of the Harary graph.

Super edge-antimagic total labeling and super edge magic labeling for subdivided stars were made in [33-35]. Javaid et al. [36] proved (a,d)-EAT labeling of extended w-trees and super edge-magic total labeling on w-trees was defined [37]. All trees are super edge magic with at most 17 vertices proven [38-39]. 


\section{Harary Graph}

For $t \geq 2$ and $p \geq 4$, a Harary graph $C_{p}^{t}$ is a graph constructed from a cycle $C_{p}$ by joining any two vertices at distance $\mathrm{t}$ in $C_{p}$.

\section{Subdivided Harary Graph}

For $t \geq 6$ and $p \geq 6$, a subdivided Harary graph $C^{t, h}$ is a graph constructed from Harary graph $C^{t}$ after the subdivision (for even $h \geq 2$ ) of each edge of graph $C_{p}^{t}$.

\section{Super (a,2)-edge Antimagic Total Labeling of Subdivided Harary Graphs}

\section{Main Results}

We prove that subdivided Harary graph is a super $(a, 2)$-edge antimagic total labeling for even $h \geq 2$.

Theorem 2.1.1. For any $p \geq 25$ with $h=2$ and for $t=6, G \cong C_{p}^{6,2}$ admits a super $(4 p+1,2)$ edge-antimagic total labeling.

Proof. Consider the vertex and edge set of $\mathrm{G}$ as $|V(G)|=p$ and $|E(G)|=q$. Let $V_{l}(G), E_{l}(G)$ and $V_{2}(G)$, $E_{2}(G)$ denote the vertices on the outer and inner cycles, respectively. The vertex $\left[V(G)=V_{l}(G) \cup V_{2}(G)\right]$ and edge $\left[E(G)=E_{1}(G) \cup E_{2}(G)\right]$ sets of $G$ are defined as follows:

$V(G)=\left\{v_{i}: 1 \leq i \leq \frac{3 p}{5}\right\} \cup\left\{v_{\alpha}^{j}: 1 \leq i \leq \frac{p}{5}, 1 \leq j \leq h\right\}$,

$E(G)=\left\{v_{i} v_{i+1}: 1 \leq i \leq \frac{3 p}{5}\right\} \cup\left\{v_{3 i-2} v_{\xi}^{1}: 1 \leq i \leq \frac{p}{5}\right\} \cup$

$\left\{v_{\xi}^{r} v_{\xi}^{r+1}: 1 \leq i \leq \frac{p}{5}, 1 \leq r \leq h-1\right\} \cup\left\{v_{\xi}^{h} v_{\eta}: 1 \leq i \leq \frac{p}{5}\right\}$,

where $\zeta=3 i-2,3 i-2+t, \eta=3 i-2+t$ and all indices are taken in mod $\frac{3 p}{5}$. Now we define labeling $\lambda: V(G) \cup$ $E(G) \rightarrow\{1,2,3, \ldots, p+q\}$. We label the vertices on outer and inner cycle as follows:

$$
\begin{aligned}
& \lambda\left(v_{i}\right)= \begin{cases}2 i-\frac{4 p}{5}+1, & \text { for } i=\frac{3 p}{5} ; \\
\frac{2 p}{5}+1+2 i, & \text { for } 1 \leq i \leq \frac{3 p}{5}-1 .\end{cases} \\
& \lambda\left(v_{\xi}^{r}\right)= \begin{cases}2 p+(4-2 s)-2 i, & \text { for } 1 \leq i \leq \frac{p}{5}, r=2 i-1, s=1 ; \\
\frac{2 p}{5}-3-2 i, & \text { for } 1 \leq i \leq \frac{p}{5}-2, r=2 ; \\
\frac{4 p}{5}-4-2 i, & \text { for } \frac{p}{5}-1 \leq i \leq \frac{3 p}{5}, r=2 .\end{cases}
\end{aligned}
$$

We label the edges on outer and inner cycle as follows: $\lambda\left(v_{i} v_{i+1}\right)= \begin{cases}\frac{16 p}{5}+2 q-3-2 i, & \text { for } \frac{3 p}{5}-1 \leq i \leq \frac{3 p}{5} \\ 2 p+2 q-3-2 i, & \text { for } 1 \leq i \leq \frac{3 p}{5}-2 .\end{cases}$ $\lambda\left(\left(v_{3 i-2} v_{\xi}^{1}\right)=\frac{12 q}{6}+1-2 i, 1 \leq i \leq \frac{p}{5}\right.$.

$\lambda\left(v_{\xi}^{r} v_{\xi}^{r+1}\right)=\frac{12 q}{6}-(3-2 s)+2 i, 1 \leq i \leq \frac{p}{5}, r=2 s-1, s=1$. $\lambda\left(v_{\xi}^{h} v_{\eta}\right)= \begin{cases}\frac{8 q}{3}-3-2 i, & \text { for } 1 \leq i \leq \frac{p}{5}-2 \\ \frac{8 q}{3}+\frac{2 p}{5}-3-2 i, & \text { for } \frac{p}{5}-1 \leq i \leq \frac{p}{5} .\end{cases}$

Edge weights of all edges in $E_{1}(G)$ will form consecutive integers $4 p+1,4 p+2, \ldots, \frac{26 p}{5}-1$, where the weight $4 p+1$ is obtained by the edge $v_{\frac{3 p}{5} 5,1}^{h} v_{1}$ if $\frac{3 p}{8} \neq t$. Edge weights of all edges in $E_{2}(G)$ will form consecutive integers $\frac{26 p}{5}, \frac{26 p}{5}+1, \frac{26 p}{5}+2, \ldots, \frac{32 p}{5}-1$. Therefore, all the edge weights form consecutive integers $4 p+1,4 p+2, \ldots, \frac{32 p}{5}-1$. Since all vertices receive smallest labels so $\lambda$ is a super $(4 p+1,2)$ edge antimagic total labeling. Fig. 2 shows super $(141,2)-E A$ T labeling of $C_{35}^{6,2}$.

Theorem 2.1.2. For any $p \geq 20 n+5$, with $h=2 n, n \geq 1$ and for $t=4 n+2, n \geq 1, G \cong C_{p}^{4 n+2,2 n}$ admits a super $(4 p+1,2)$ edge-antimagic total labeling.

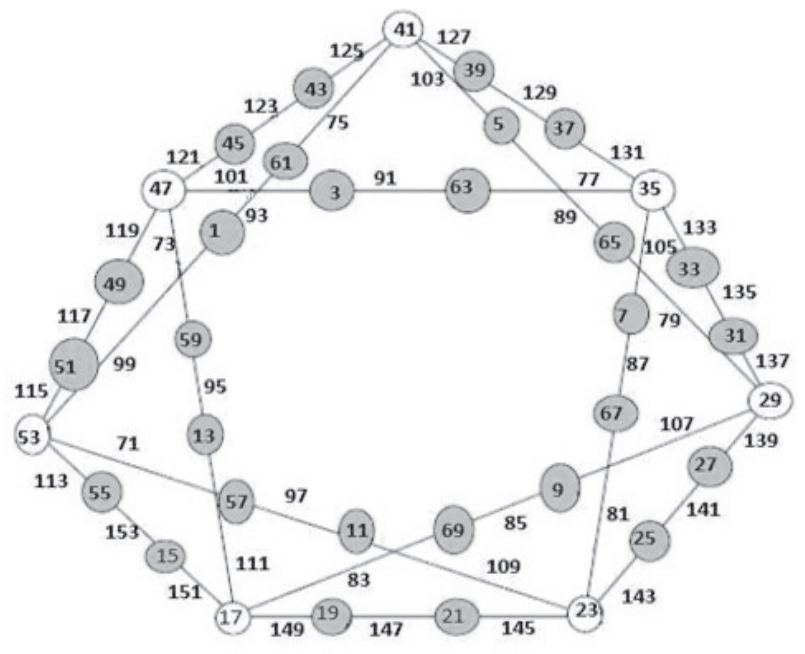

Fig. 2. Super (141,2)-EAT labeling of $C_{35}^{6,2}$. 
Proof. Let us denote the vertex and edge set of $\mathrm{G}$ as $|V(G)|=p$ and $|E(G)|=q$. Let $V_{l}(G), E_{l}(G)$ and $V_{2}(G)$, $E_{2}(G)$ denote the vertices on the outer and inner cycles, respectively. The vertex $\left[V(G)=V_{l}(G) \cup V_{2}(G)\right]$ and edge $\left[E(G)=E_{1}(G) \cup E_{2}(G)\right]$ sets of $G$ are defined as follows:

$$
\begin{gathered}
V(G)=\left\{v_{i}: 1 \leq i \leq \frac{(2 n+1) p}{4 n+1}, n \geq 1\right\} \cup\left\{v_{\alpha}^{j}: 1 \leq i \leq \frac{p}{4 n+1},\right. \\
1 \leq j \leq h, n \geq 1\}, \\
E(G)=\left\{v_{i} v_{i+1}: 1 \leq i \leq \frac{(2 n+1) p}{4 n+1}, n \geq 1\right\} \cup \\
\left\{v_{(2 n+1) i-2 n} v_{\alpha}^{1}: 1 \leq i \leq \frac{p}{4 n+1}, n \geq 1\right\} \\
\cup\left\{v_{\alpha}^{j} v_{\alpha}^{j+1}: 1 \leq i \leq \frac{p}{4 n+1}, 1 \leq j \leq h-1, n \geq 1\right\} \cup \\
\left\{v_{\alpha}^{h} v_{\beta}: 1 \leq i \leq \frac{p}{4 n+1}, n \geq 1\right\},
\end{gathered}
$$

where $\alpha=(2 n+1) i-2 n,(2 n+1) i-2 n+t, \beta=(2 n+1)$ $i-2 n+t$ and all indices are taken in $\bmod \frac{(2 n+1) p}{4 n+1}, n \geq 1$.

Now we define labeling $\lambda: V(G) \cup E(G) \rightarrow\{1,2,3, \ldots$, $p+q\}$. We label the vertices on outer and inner cycle as follows:

$\lambda\left(v_{i}\right)=$

$\begin{cases}2 i-\frac{(2 n+2) p}{4 n+1}+2 n-1, & \frac{(2 n+1) p}{4 n+1}-(n-1) \leq i \leq \frac{(2 n+1) p}{4 n+1}, n \geq 1 \\ \frac{2 n p}{4 n+1}+2 n-1+2 i, & 1 \leq i \leq \frac{(2 n+1) p}{4 n+1}-n, n \geq 1 .\end{cases}$

$\lambda\left(v_{\alpha}^{j}\right)=$

$\left[2 p+\gamma, \quad 1 \leq i \leq \frac{p}{4 n+1}, j=2 k-1,1 \leq k \leq n, n \geq 1 ;\right.$

$\frac{(2 n+2) p}{4 n+1}+\gamma, \quad 1 \leq i \leq \frac{p}{4 n+1}, j=2 k, 1 \leq k \leq n-1, n \geq 2 ;$

$\left\{\frac{2 n p}{4 n+1}-\delta, \quad 1 \leq i \leq \frac{p}{4 n+1}-2, j=h, n \geq 1 ;\right.$

$\frac{4 n p}{4 n+1}-\delta, \quad \frac{p}{4 n+1}-1 \leq i \leq \frac{p}{4 n+1}, j=h, n \geq 1$,

where $\gamma=(2 n-2 k+1)-2 n i$ and $\delta=(4 n-1)+2 n i$. The edges on the outer and inner cycles are labelled as:

$$
\begin{aligned}
& \lambda\left(v_{k} v_{k+1}\right)= \\
& \left\{\begin{array}{l}
\frac{(12 n+4) p}{4 n+1}+2 q-(2 n+1)-2 i, \quad \frac{(2 n+1) p}{4 n+1}-n \leq i \leq \frac{(2 n+1) p}{4 n+1}, n \geq 1 ; \\
2 p+2 q-(2 n+1)-2 i, \quad 1 \leq i \leq \frac{(2 n+1) p}{4 n+1}-(n+1), n \geq 1 .
\end{array}\right. \\
& \lambda\left(v_{(2 n+1) i-2 n} v_{\alpha}^{j}\right)=\frac{(10 n+2) q}{4 n+2}+1-2 n i, 1 \leq i \leq \frac{p}{4 n+1}, n \geq 1 . \\
& \lambda\left(v_{\alpha}^{j} v_{\alpha}^{j+1}\right)= \\
& \left\{\begin{array}{l}
\frac{(10 n+2) q}{4 n+2}-\zeta, \quad 1 \leq i \leq \eta, j=2 k-1,1 \leq k \leq n, n \geq 1 ; \\
\frac{(8 n+2) q}{4 n+2}-\rho, \quad 1 \leq i \leq \eta, j=2 k, 1 \leq k \leq n-1, n \geq 2,
\end{array}\right.
\end{aligned}
$$

where $\zeta=(2 n-2 k+1)-2 n i, \rho=(2 n-1-2 k)-2 n i$ and $\eta=\frac{\xi}{4 n+1}$

$\lambda\left(v_{\alpha}^{h} v_{\beta}\right)= \begin{cases}\frac{(6 n+2) q}{2 n+1}-3-2 i, & 1 \leq i \leq \frac{p}{4 n+1}-2, n \geq 1 \\ \frac{(6 n+2) q}{2 n+1}+\frac{2 p}{4 n+1}-3-2 i, & \frac{p}{4 n+1}-1 \leq i \leq \frac{p}{4 n+1}, n \geq 1 .\end{cases}$

Edge weights of all edges in $E_{l}(G)$ will form consecutive integers $4 p+1,4 p+2, \ldots, \frac{(20 n+6) p}{4 n+1}-1, n \geq 1$, where the weight $4 p+1$ is obtained by the edge $v_{\frac{(2 n+1) p}{4 n+1}-(4 n+1), 1}^{h} v_{1}$, if $\frac{(2 n+1) p}{6 n+2} \neq t, n \geq 1$. Edge weights of all edges in $E_{2}(G)$ will form consecutive integers $\frac{(20 n+6) p}{4 n+1}, \frac{(20 n+6) p}{4 n+1}+1, \ldots, \frac{(24 n+8) p}{4 n+1}-1, n \geq 1$.

Therefore, all the edge weights form consecutive integers $4 p+1,4 p+2, \ldots, \frac{(24 n+8) p}{4 n+1}-1, n \geq 1$. Since all vertices receive the smallest labels, $\lambda$ is a super $(4 p+1,2)$ EAT labeling.

Theorem 2.1.3. For any even $p, p \geq 16$ with $h=2$ and for any $t$ (which is multiple of 3 ), $t \geq 6, G \cong C_{p}^{t 2}$ admits a super $(4 p+1,2)$ edge-antimagic total labeling.

Proof. Let us denote the vertex and edge set of $\mathrm{G}$ as $|V(G)|=p$ and $|E(G)|=q$. Let $V_{l}(G), E_{1}(G)$ and $V_{2}(G)$, $E_{2}(G)$ denote the vertices on the outer and inner cycles, respectively. The vertex $\left[V(G)=V_{l}(G) \cup V_{2}(G)\right]$ and edge $\left[E(G)=E_{l}(G) \cup E_{2}(G)\right]$ sets of $G$ are defined as follows:

$$
\begin{gathered}
V(G)=\left\{v_{i}: 1 \leq i \leq \frac{3 p}{4}\right\} \cup\left\{v_{\alpha}^{j}: 1 \leq i \leq \frac{p}{8}, 1 \leq j \leq h\right\}, \\
E(G)=\left\{v_{i} v_{i+1}: 1 \leq i \leq \frac{3 p}{4}\right\} \cup\left\{v_{3 i-2} v_{\alpha}^{1}: 1 \leq i \leq \frac{p}{8}\right\} \\
\cup\left\{v_{\alpha}^{j} v_{\alpha}^{j+1}: 1 \leq i \leq \frac{p}{8}, 1 \leq j \leq h-1\right\} \\
\cup\left\{v_{\alpha}^{h} v_{\beta}: 1 \leq i \leq \frac{p}{8}\right\}
\end{gathered}
$$

where $\alpha=3 i-2,3 i-2+t, \beta=3 i-2+t$ and all indices are taken in mod $\frac{3 p}{4}$. Now we define labeling $\lambda: V(G) \cup$ $E(G) \rightarrow\{1,2,3, \ldots, p+q\}$. We label the vertices on outer and inner cycle as follows: 
$\lambda\left(v_{i}\right)= \begin{cases}2 i-\frac{10 p}{8}+1, & \text { for } i=\frac{3 p}{4} \\ \frac{2 p}{8}+1+2 i, & \text { for } 1 \leq i \leq \frac{3 p}{4}-1 .\end{cases}$

$\lambda\left(v_{\alpha}^{j}\right)= \begin{cases}2 p+(3-2 k)-2 i, & \text { for } 1 \leq i \leq \frac{p}{8}, j=2 k-1, k=1 ; \\ \frac{4 p}{8}-3-2 i, & \text { for } 1 \leq i \leq \frac{p}{8}, j=2 k, k=1 .\end{cases}$

The edges on outer cycle and inner cycle are labelled as:

$$
\begin{aligned}
& \lambda\left(v_{i} v_{i+1}\right)= \begin{cases}\frac{14 p}{4}+2 q-3-2 i, & \text { for } \frac{3 p}{4}-1 \leq i \leq \frac{3 p}{4} ; \\
2 p+2 q-3-2 i, & \text { for } 1 \leq i \leq \frac{3 p}{4}-2 .\end{cases} \\
& \lambda\left(v_{3 i-2} v_{\alpha}^{j}\right)=\frac{18 q}{9}+1-2 i, 1 \leq i \leq \frac{p}{8} . \\
& \lambda\left(v_{\alpha}^{j} v_{\alpha}^{j+1}\right)=\frac{18 q}{9}-(3-2 k)+2 i, 1 \leq i \leq \frac{p}{8}, j=2 k-1, k=1 . \\
& \lambda\left(v_{\alpha}^{h} v_{\beta}\right)=\frac{22 q}{9}+\frac{2 p}{8}-3-2 i, 1 \leq i \leq \frac{p}{8} .
\end{aligned}
$$

$E_{l}(G)$ has edge weights of all edges form consecutive integers as: $4 p+1,4 p+2, \ldots, \frac{38 p}{8}-1$,

where the weight $4 p+1$ is obtained by the edge $v_{1, \frac{3 p}{8}+1}^{h} v_{\frac{3 p}{8}+1}$ if $\frac{3 p}{8}=t$.

$E_{2}(G)$ has edge weights of all edges form consecutive integers as: $\frac{38 p}{8}, \frac{38 p}{8}+1, \frac{38 p}{8}+2, \ldots, \frac{50 p}{8}-1$.

Combining both the sequences $E_{1}(G)$ and $E_{2}(G)$ as: $4 p+1,4 p+2, \ldots, \frac{50 p}{8}-1$.

As all vertices obtain the smallest labels, so $\lambda$ is a super $(4 p+1,2)$-EAT labeling (Fig. 3$)$.

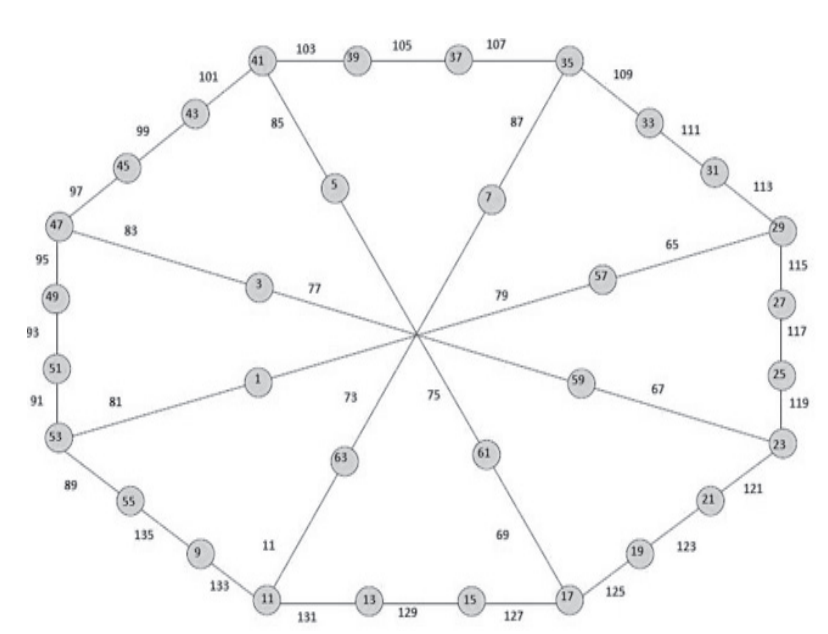

Fig. 3. Super (161, 2)-EAT labeling of $C_{40}^{12,2}$.
Theorem 2.1.4. For any even $p, p \geq 12 n+4$ with $h=2 n, n \geq 1$ and for any $t$ (which is multiple of $2 n+1$ ), $\mathrm{t} \geq 4 n+2, n \geq 1, G \cong C_{p}^{t 2 n}$ admits a super $(4 p+1,2)$ edgeantimagic total labeling.

Proof. Let us denote the vertex and edge set of $\mathrm{G}$ as $|V(G)|=p$ and $|V(G)|=q$. Let $V_{1}(G), E_{1}(G)$ and $V_{2}(G)$, $E_{2}(G)$ denote the vertices on the outer and inner cycles, respectively. The vertex $\left[V(G)=V_{l}(G) \cup V_{2}(G)\right]$ and edge $\left[E(G)=E_{1}(G) \cup E_{2}(G)\right]$ sets of $G$ are defined as follows:

$$
\begin{gathered}
V(G)=\left\{v_{i}: 1 \leq i \leq \frac{(2 n+1) p}{3 n+1}, n \geq 1\right\} \\
\cup\left\{v_{\alpha}^{j}: 1 \leq i \leq \frac{p}{6 n+2}, 1 \leq j \leq h, n \geq 1\right\}, \\
E(G)=\left\{v_{i} v_{i+1}: 1 \leq i \leq \frac{(2 n+1) p}{3 n+1}, n \geq 1\right\} \\
\cup\left\{v_{(2 n+1) i-2 n} v_{\alpha}^{1}: 1 \leq i \leq \frac{p}{6 n+2}, n \geq 1\right\} \\
\cup\left\{v_{\alpha}^{j} v_{\alpha}^{j+1}: 1 \leq i \leq \frac{p}{6 n+2}, 1 \leq j \leq h-1, n \geq 1\right\} \\
\cup\left\{v_{\alpha}^{h} v_{\beta}: 1 \leq i \leq \frac{p}{6 n+2}, n \geq 1\right\},
\end{gathered}
$$

where $\alpha=(2 n+1) i-2 n,(2 n+1) i-2 n+t, \beta=(2 n+$ $1) i-2 n+t$ and all indices are taken in $\bmod \frac{(2 n+1) p}{3 n+1}$, $n \geq 1$. Now we define labeling $\lambda: V(G) \cup E(G) \rightarrow\{1,2,3, \ldots$, $p+q\}$. We label the vertices on outer and inner cycle as follows:

$\lambda\left(v_{i}\right)= \begin{cases}2 i-\frac{(6 n+4) p}{6 n+2}+2 n-1, & \frac{(2 n+1) p}{3 n+1}-(n-1) \leq i \leq \frac{(2 n+1) p}{3 n+1}, \forall n \geq 1 ; \\ \frac{2 n p}{6 n+2}+2 n-1+2 i, & 1 \leq i \leq \frac{(2 n+1) p}{3 n+1}-n, \forall n \geq 1 .\end{cases}$

$\lambda\left(v_{\alpha}^{j}\right)= \begin{cases}2 i+\gamma, & 1 \leq i \leq \frac{p}{6 n+2}, j=2 k-1,1 \leq k \leq n, n \geq 1 ; \\ \frac{(2 n+2) p}{6 n+2}+\gamma, & 1 \leq i \leq \frac{p}{6 n+2}, j=2 k, 1 \leq k \leq n, n \geq 1,\end{cases}$

where $\gamma=(2 n-2 m+1)-2 n i$. We label the edges on outer and inner cycles as follows:

$\lambda\left(v_{i} v_{i+1}\right)= \begin{cases}\frac{(10 n+4) p}{3 n+1}+2 q-(2 n+1)-2 i, & \frac{(2 n+1) p}{3 n+1}-n \leq i \leq \frac{(2 n+1) p}{3 n+1}, n \geq 1 ; \\ 2 p+2 q-(2 n+1)-2 i, & 1 \leq i \leq \frac{(2 n+1) p}{3 n+1}-(n+1), n \geq 1 .\end{cases}$

$\lambda\left(v_{(2 n+1) i-2 n} v_{\alpha}^{j}\right)=\frac{(14 n+4) q}{6 n+3}+1-2 n i, 1 \leq i \leq \frac{p}{6 n+2}, n \geq 1$.

$\lambda\left(v_{\alpha}^{j} v_{\alpha}^{j+1}\right)= \begin{cases}\frac{(14 n+4) q}{6 n+3}-\delta, & 1 \leq i \leq \frac{p}{6 n+2}, j=2 k-1,1 \leq k \leq n, n \geq 1 ; \\ \frac{(12 n+4) q}{6 n+3}-\zeta, & 1 \leq i \leq \frac{p}{6 n+2}, j=2 k, 1 \leq k \leq n-1, n \geq 2,\end{cases}$

where $\delta=(2 n+1-2 k)-2 n i$ and $\zeta=(2 n-2 k+1)-2 n i$. $\lambda\left(v_{\alpha}^{h} v_{\beta}\right)=\frac{(16 n+6) q}{6 n+3}+\frac{2 p}{6 n+2}-3-2 i, 1 \leq i \leq \frac{p}{6 n+2}, n \geq 1$

Edge weights of all edges in $E_{l}(G)$ will form consecutive integers $4 p+1,4 p+2, \ldots, \frac{(28 n+10) p}{6 n+2}-1, n \geq 1$, where the weight $4 p+1$ is obtained by the edge 
$v_{1, \frac{(2 n+1) p}{6 n+2}+1}^{h} \frac{v_{(2 n+1) p}}{6 n+2}+1$ if $\frac{(2 n+1) p}{6 n+2}=t, n \geq 1$. Edge weights of

all edges in $E_{2}(G)$ will form consecutive integers $\frac{(28 n+10) p}{6 n+2}, \frac{(28 n+10) p}{6 n+2}+1, \ldots, \frac{(36 n+14) p}{6 n+2}-1, \quad n \geq 1$.

Therefore, all the edge weights form consecutive integers $4 p+1,4 p+2, \ldots, \frac{(36 n+14) p}{6 n+2}-1, n \geq 1$. Since all vertices receive smallest labels, $\lambda$ is a super $(4 p+1,2)$-EAT labeling.

This work focuses on landscape connectivity as it is an important part of biodiversity preservation efforts. It subsidizes the assurance of approach to the genetic variability and persistence of extinct biota, which helps stabilize the adverse effects of habitat crumbling. It is also affected regarding species range in response to climatic diversification.

The application of graph-theory, particularly Harary graph, has been endorsed in the last decade for this purpose [41-45]. This can work as an effective analytical tool for the study of the landscape fragmentation effects on the fauna and to augment the selection of reserve networks. Particularly, the graph structures have been revealed to be an influential way of modeling landscape networks and performing complex analysis regarding [46].

The advantage of a graph-theory application over the other techniques is the special framework that is made applicable to very small sets of data. Graph theory can be applied for huge populations and also provide leverage on applications concerned with landscape connectivity [4248].

\section{Conclusions}

This model is an effective approach for landscape connectivity in an authentic and reliable way. Graph theory and its implementation through subdivision of a Harary graph by antimagic total labeling helps to develop connectivity responses and to reduce the uncertainty associated with previous models. The hour is to preserve and protect the surface and subsurface environment without disturbing the original character of the region. Keeping this in view, landscape connectivity by using this graphic approach and design is worth applicable.

\section{References}

1. CETIN M. Using GIS analysis to assess urban green space in terms of accessibility: case study in Kutahya. Int. J. Sust. Dev. World Ecol. 22 (5), 420, 2015.

2. CETIN M. Sustainability of Urban Coastal Area Management: A Case Study on Cide, J. Sustain. For. 35 (7), 527, 2016.
3. CETIN M. Consideration of permeable pavement in landscape architecture. J. Environ. Prot. Ecol. 16 (1), 385, 2015.

4. CETIN M. Determination of bioclimatic comfort areas in landscape planning: A case study of Cide Coastline. Turk. J. Agric. Food Sci. Tech. 4 (9), 800, 2016.

5. CETIN M. Evaluation of the sustainable tourism potential of a protected area for landscape planning: a case study of the ancient city of Pompeipolis in Kastamonu. Int. J. Sust. Dev. World Ecol. 22 (6), 490, 2015.

6. CETIN M. Determining the bioclimatic comfort in Kastamonu City. Environ. Monit. Assess. 187 (10), 640, 2015.

7. CETIN M., ADIGUZEL F., KAYA O., SAHAP A. Mapping of bioclimatic comfort for potential planning using GIS in Aydin. Environ. Dev. Sustain. 1-15, 2016 doi: 10. 1007/ s10668-016-9885-5

8. CETIN M., SEVIK H. Evaluating the recreation potential of Ilgaz Mountain National Park in Turkey. Environ. Monit. Assess. 188 (1), 52, 2016.

9. UKPAKA C. Development of model for bioremediation of crude oil using moringa extract. Chem. Int. 2, 19, 2016b.

10. UKPAKA C. Empirical model approach for the evaluation of $\mathrm{pH}$ and conductivity on pollutant diffusion in soil environment. Chem. Int. 2, 267, 2016c.

11. UKPAKA C. Predictive model on the effect of restrictor on transfer function parameters on pneumatic control system. Chem. Int. 2, 128, 2016d.

12. UKPAKA C., ADAOBI SNA. Development and evaluation of trans-amadi groundwater parameters: The integration of finite element techniques. Chem. Int. 3, 306, 2017.

13. ALI T.A., MORTULA M., ATABAY S. GIS-based Study on the Susceptibility of Dubai Creek (UAE) to Eutrophication. Pol. J. Environ. Stud. 25 (6), 2275, 2016.

14. PETROSIAN H., KAR A.D., ASHRAFI S., FEGHHI J. Investigating Environmental Factors for Locating Mangrove Ex-situ Conservation Zones Using GIS Spatial Techniques and the Logistic Regression Algorithm in Mangrove Forests in Iran. Pol. J. Environ. Stud. 25 (5), 2097, 2016.

15. HOU K., LI X., WANG J., ZHANG J. Evaluating Ecological Vulnerability Using the GIS and Analytic Hierarchy Process (AHP) Method in Yan'an, China. Pol. J. Environ. Stud. 25 (2), 599, 2016.

16. ILIĆ I., VUKOVIĆ M., ŠTRBAC N., UROŠEVIĆ S. Applying GIS to Control Transportation Air Pollutants. Pol. J. Environ. Stud. 23 (5), 1849, 2014.

17. RAHMONOV O., GAJOS M., CZUBAN R., PARUSEL T. GIS Methods in Monitoring Succession Processes in Limestone and Dolomite Quarries. Pol. J. Environ. Stud. 23 (2), 647, 2014

18. MINOR E.S., URBAN D. Graph theory as a proxy for spatially explicit population models in conservation planning. Ecological Applications. 17, 1771, 2007.

19. GALPERN P., MANSEAU M., FALL A. Patch-based graphs of landscape connectivity: A guide to construction, analysis and application for conservation. Biological Conversions 144, 44, 2011.

20. GASTNER M.T., NEWMAN M.E.J. The spatial structure of networks. European Physical Journal B. 49, 247, 2006.

21. ZETTERBERG A., MÖRTBERG U.M., BALFORS B. Making graph theory operational for landscape ecological assessments, planning, and design. Landscape and Urban Planning, 95, 181, 2010.

22. FIGUEROA-CENTENO R.M., ICHISHIMA R., MUNTANER-BATLE F.A. The place of super edge-magic 
labelings among other classes of labelings. Discrete Math. 231, 153, 2001.

23. FANHUA KONG F., YIN H., NAKAGOSHI N., ZONG Y. Urban green space network development for biodiversity conservation: Identification based on graph theory and gravity modeling. Landscape and Urban Planning, 95, 16, 2010.

24. LORO M., ORTEGA E., ARCE R.M., GENELETTI D. Ecological connectivity analysis to reduce the barrier effect of roads. An innovative graph-theory approach to define wildlife corridors with multiple paths and without bottlenecks. Landscape and Urban Planning, 139, 149, 2015.

25. PHILLIPS J.D., SCHWANGHART W., HECKMANN T. Graph theory in the geosciences. Earth-Science Reviews, 143, 147, 2015.

26. NGURAH A.A.G., SIMANJUNTAK R., BASKORO E.T. Super (a, d) -EMT labeling of subdivision of $K_{\{1,3\}}$. SUT J. Math.\}. 43, 127, 2007.

27. KIM H.K., KOOLEN J.H., YANG J.Y. Structure theory for graphs with fixed smallest eigenvalue. Linear Algebra and its Applications, 504, 1, 2016.

28. KEOWN C.L., DATKO M.C., CHEN C.P., MAXIMO J.O., JAHEDI A., MÜLLER R-A. Network Organization Is Globally Atypical in Autism: A Graph Theory Study of Intrinsic Functional Connectivity. Biological Psychiatry: Cognitive Neuroscience and Neuroimaging, 2, 66, 2017.

29. SIMANJUNTAK R., MILLER M. Survey of $(a, d)$-EAT graph labelings. MIHMI. 6, 179, 2000.

30. SIMANJUNTAK R., BERTAULT F., MILLER M. Two new (a,d) -EAT graph labelings. Proc. of Eleventh Austrailian Workshop of Combinatorial Algorithm. 179, 2000.

31. FOLTÊTE J.-C., GIRAUDOUX P. A graph-based approach to investigating the influence of the landscape on population spread processes Ecological Indicators, 18, 684, 2012.

32. HUSSAIN M., BASKORO E.T., ALI K. Super $(\mathrm{a}, \mathrm{d})$ antimagic total labeling of Harary graph. Ars Combinatoria. 104, 225, 2012.

33. JAVAID M., MAHBOOB S., MAHBOOB A., HUSSAIN M. On (Super) edge-antimagic total labeling of subdivided stars. International Journal of Mathematics and Soft Computing. 4, 73, 2014.

34. SALMAN A.N.M., NGURAH A.A.G., IZZATI N. On super edge-magic total labeling of a subdivision of a star $S_{n}$. Utiltas Mathematica. 81, 275, 2010.

35. BHATTI A.A., JAVAID M. Super EAT labeling of subdivided stars. J. Indones.Math.Sec. 19, 67, 2013.

36. JAVAID M, BHATTI AA, HUSSAIN M. (a,d) - EAT labeling of extended -trees. Utiltas Mathematica. 87, 293, 2012.
37. JAVAID M., HUSSAIN M., ALI K, DAR K.H. Super edgemagic total labeling on -trees. Utiltas Mathematica. 86, 183, 2011.

38. LEE S.M., SHAN Q.X. All trees with at most 17 vertices are super edgemagic. $16^{\text {th }}$ MCCCC Confernece, Carbondale, University Southern Illinois. 2002.

39. RABINOWITZ A., ZELLER K.A. A range-wide model of landscape connectivity and conservation for the jaguar, Panthera onca. Biological Conservation, 143, 939, 2010.

40. LIU S., DONG Y., DENG L., LIU Q., ZHAO H., DONG $\mathrm{S}$. Forest fragmentation and landscape connectivity change associated with road network extension and city expansion: A case study in the Lancang River Valley. Ecological Indicators, 36, 160, 2014.

41. THOMAS C.J., LAMBRECHTS J., WOLANSKI E., TRAAG V.A., BLONDEL V.D., DELEERSNIJDER E., HANERT E. Numerical modelling and graph theory tools to study ecological connectivity in the Great Barrier Reef. Ecological Modelling, 272, 160, 2014.

42. FORTIN M.-J., JAMES P.M.A., MACKENZIE A., MELLES S.J., RAYFIELD B. Spatial statistics, spatial regression, and graph theory in ecology. Spatial Statistics, 1, 100, 2012.

43. QI K., FAN Z., NG C.N., WANG X., XIE Y. Functional analysis of landscape connectivity at the landscape, component, and patch levels: A case study of Minqing County, Fuzhou City, China. Applied Geography, 80, 64, 2017.

44. CHEN T., SUN Z., WU B. Stability of multi-group models with cross-dispersal based on graph theory. Applied Mathematical Modelling, 47, 745, 2017.

45. MAYVAN B.B., RASOOLZADEGAN A. Design pattern detection based on the graph theory. Knowledge-Based Systems, 120, 211, 2017.

46. URBAN D.L., MINOR E.S., TREML E.A., SCHICK R.S. Graph models of habitat mosaics. Ecol. Lett. 12, 260, 2009.

47. LUQUE S., SAURA S., FORTIN M.-J. Landscape connectivity analysis for conservation: insights from combining new methods with ecological and genetic data. Landscape Ecol. 27, 153, 2012.

48. RUDNICK D.A., RYAN S.J., BEIER P., CUSHMAN S.A., DIEFFENBACH F., EPPS C.W., GERBER L.R., HARTTER J., JENNESS J.S., KINTSCH J., MERENLENDER A.M., PERKL R.M., PREZIOSI D.V., TROMBULAK S.C. The Role of Landscape Connectivity in Planning and Implementing Conservation and Restoration Priorities. Issues in Ecol. 16, 1, 2012. 